be successfully treated with rough movementswrenching, pulling, and twisting The cases that are thus curable $I$ have endeavoured to point out to you. Be on the watch for them. But remember always that what may be treated violently may be treated more safely and as successfully with comparative gentleness; and that, in some cases, you may very advantageously use chloroform or ether. And remember, also, that no degree of violence, not even such movements or exercises as I have advised, can be generally safe in the treatment of injured joints, unless when directed with a skilful discernment of the appropriate cases.

Learn then to imitate what is good and avoid what is bad in the practice of bone-setters; and, if you would still further observe the rule, Fas est $a b$ hoste doceri, which is in no calling wiser than in ours, learn next what you can from the practice of rubbers and plaisterers: for these also know many clever tricks; and, if they had but educated brains to guide their strong and pliant hands, they might be most skilful curers of bad joints and many other hindrances of locomotion.

\section{CHOLERA IN PRISON.}

\section{By ROBERT CHRISTISON, M.D., F.R.S.E., Professor of Materia Medica in the University of Edinburgh, etc.}

THe following case of cholera, with the introductory observations, was sent for communication to the last meeting of the British Medical Association in August; but no opportunity occurred for communicating it. The manuscript was subsequently mislaid; but, being recovered, was thought deserving still of being published. Although some part of the objects of the paper cannot now be attained by it, there are obvious reasons why it should appear as originally drawn up. I shall only add, that a second fatal case occurred three months later in circumstances precisely similar. This case $\mathrm{I}$ have requested $\mathrm{Mr}$. Thomson, the Surgeon of the Prison, to communicate also.-December 22nd, 1866.

In numerous observations which have lately appeared on malignant cholera in the medical journals and the London newspapers, and especially in recent reports issued by authority of Government, it seems to be taken as proved that this fearful disease is entirely of foreign origin, that it arises only by communication from the sick to the healthy, and that this property depends on transmission of germs existing in the discharges from the bowels. Accordingly, the practical inference follows, that, by a sufficiently stringent quarantine, the malady may be kept out of the British islands.

I apprehend, however, that these conclusions have been come to hastily, by looking at the questions involved in them in a one-sided way, and to the disregard of important facts, opposite in their bearing, which have been accurately ascertained in former epidemics of cholera. That the disease may be communicated from the sick to the healthy $I$ am far from denying : I have myself seen cases which could not, as I thought, be reasonably referred to any other origin. But that the generality of cases of malignant cholera can be logically traced to the same origin, is a very doubtful proposition.

The question, I need not say, is one of great prac- tical importance at the present time; and now is the time for deciding it. For it is mainly by studying with scrupulous exactitude the circumstances of the very first outbreak in localities at a considerable distance from any known seats of the disease, that we can arrive at a sufficient number of well-ascertained facts for ruling our conclusions.

It may be well to lay down beforehand the conditions for giving conclusiveness, either the one way or the other, to facts of the kind; which there is every reason now to fear will present themselves in ample number to competent observers. This is a precautionary measure, to which it appears to me the British Medical Association may, with great advantage, turn its attention at its present meeting. I cannot myself make the attempt, for want of adequate leisure; but it will be in much better hands, if the Association see cause for taking it up.

In the meantime I beg to present a single case, which, as far as a single case can go, supports power. fully the doctrine that malignant cholera may arise, not only without communication from a previous case, but likewise in apparent absence of all the other causes, exciting and predisposing too, which have been variously supposed to create or to favour cholera.

I have on several occasions, in periods when malignant cholera was not known to prevail anywhere in Great Britain, met with cases which were undistinguishable from that disease, in any other respect except that they recovered. In the following instance the identity with one of the worst forms of malignant cholera was complete, in as much as the sufferer died in twenty-three hours.

The person attacked was a man under middle age, a criminal lunatic, who had been for several years confined as such in the lunatic department of the General Prison at Perth. This is a prison of comparatively recent erection, for the custody of criminals from all the local prisons of Scotland, who are sentenced to long terms of imprisonment. The prisoners amount to nearly eight hundred. There is a special department, a separate building, for criminal lunatics of both sexes. The building now in use is a new one, which has been fitted up with every modern convenience commonly adopted in ordinary lunatic asylums, in so far as compatible with the sure custody of a class of lunatics most of whom are dangerous. The success of the managers and prison-officers has been very great; because for many years the health of every class of prisoners has been uncommonly good. On June 30th, I inspected the prison, and especially the lunatic department, as I do by order of the prison authorities every alternate month. I reported the whole prison on that occasion as being in an extraordinary state of health: Among rearly eight hundred prisoners; there were only two women and five men confined to bed, two of the latter for hernia humoralis merely. There was no tendency to diarrhoea or stomach ailments in any part of the prison; no case of diarrhoea had occurred among the lunatics. I may here anticipate dates so far as to dispose of this branch of the subject by also mentioning, that during a few days after the man's death, two cases of slight diarrhoa, and one of slight stomach complaint, did occur among the male lunntics, thirty-four in number; that these ailments were easily cured by simple means; and that no similar case had happened when I last heard of the condition of the prisoners, on August 1st, three weeks after the man's death.

He was a tall, erect, strong, active, obliging man, always very healthy physically. My attention happened to be drawn to him particularly during my visit on June 30th, when he had every appearance of 
excellent bodily health. He was in the same state all Monday, July 9th. The rules and customs of the lunatic department of the prison are such as render it scarcely possible that he could have had any diarrhoa without the warders observing it. In the evening he went to bed in his usual good state of health. About half-past four in the morning of the 10th, the attention of the warders was first turned to him as affected with vomiting and purging. Mr. Christie of Perth was sent for in the temporary absence of the medical officer of the prison, and saw him in little more than an hour. This gentleman visited him frequently afterwards; and seeing at once the extreme urgency of the case, he obtained also the aid of Dr. Absolon of Perth. Both gentleman had no doubt from the first that the man was struck down with malignant cholera.

Every essential symptom was present, or very soon ensued. There was frequent vomiting and purging of a watery stuff like rice-water; coldness of the extremities, tongue, and breath; blueness of the skin, shrinking of the features, and hollowness of the eyes, cold, clammy sweat, cramps of the arms and limbs, huskiness of the voice, a feeble, hurried pulse, and total suppression of urine. To these facts let me add, that both Dr. Absolon and Mr. Christie were well acquainted with the characters of the disease from familiar observation of it in two epidemics.

The treatment adopted consisted of small doses of calomel and opium, small doses of arsenical solution, which, in the last cholera epidemic, Mr. Christie had found to be an useful remedy to arrest vomiting, brandy also in small quantity from time to time, and heat applied to the extremities and trunk of the body. The most urgent symptoms were thus allayed for a time, and the man's weakness, which at first was so great that it was judged unsafe to attempt his removal from the Asylum dormitory, became so much less that he was carried without difficulty to a room in a detached building hard by. But although his sufferings were relieved, the symptoms continued essentially the same; extreme prostration set in, and about half-past three in the morning of the 11th he died, evidently labouring under symptoms undistinguishable from those of violent malignant cholera.

On visiting the prison next day, I was assisted in my inquiries by Mr. Christie, and also by $\mathrm{Mr}$. Thomson, the prison-surgeon. Notwithstanding their aid, and especially that of Mr.Thomson, who is most intimately acquainted with every particular connected with the structure of the prison, and of the prison discipline, bearing on the several questions which arise in this case, I am obliged to confess that my endeavours to discover a cause for this attack, whether exciting, or even predisposing, have been in vain.

Communication from without seems out of the question; except the officers of the prison, who were all at the time in good health, no one is admitted into the prison without an order from the prison's managers, and no stranger had visited the lunatic department for a considerable time. Setting aside, however, the extreme difficulty and unlikelihood of any secret communication from without, with the lunatic prisoners in any circumstances, $I$ must observe that I have not yet heard of any previous case of malignant cholera having occurred in Scotland since the news of its appearance in Germany and Holland, except on board of two vessels in Leith harbour, about forty-five miles distant from Perth.

During the day preceding the date of the man's seizure, nothing had been supplied from the establishment of the prison in the way of food, except the ordinary fare of the lunatic department, as well as of the prisoners generally; and water had been his only drink as usual. I found no reason to suspect that he had been supplied with any article from without. He had taken a good deal of exercise on the day before his illness; but the weather was by no means very hot, though it became so next day, nor was he ever overheated, nor observed to drink more than usual. He slept on the night of his illness, as he had always done, with eleven other lunatics, in a dormitory, the cubic space of which is about 1,400 feet for each, the ventilation well provided for, and the temperature that night from $64^{\circ}$ to $66^{\circ}$.

I examined the water with which the lunatic department is supplied. It is pumped from a well about thirty feet from the bank of the Tay, after the tidal water in ebb-tide has left the river. It was quite limpid and colourless, free from odour and taste, pleasant to drink, sufficiently soft, and impregnated with very little saline matter, of which the principal ingredients are carbonate and sulphate of lime ; it is undoubtedly a water of good quality.

The building is founded on alluvial gravel, and is thoroughly well drained; the water-closets were in good working condition. On June 23rd, however, seventeen days before the man took ill, the drain from those in the men's department having been choked by some washing-cloths, which had been thrown down into it, it was immediately opened for about two hours, near the door of the building, and cleared of all obstruction. This fact may perhaps satisfy the extreme party who refer cholera invariably to filth and foul odour. To myself, such reference in the case would appear sheer credulity. Theshortness of the obstruction, the freshness of the obstructing matter, the length of time before seizure, and the immunity of the other prisoners, are overwhelming facts in the way.

The tail-race of the "town's mill-lade," a stream which receives part of the sewage of the city, and the discharges from some dye-works and bleach-fields, and which contains impurities both organic and inorganic, passes round the prison-walls on two sides; this stream has occasionally proved a nuisance by its odour, and was slightly so a few days before the man's illness; but the lunatic establishment stands at the extreme distance from this stream, 191 yards from it, and separated by the entire main buildings of the prison.

Searching for all possible sources of malaria, my attention was turned to a sunk midden for the household waste of the warders' houses, a square pit covered by a wooden trap, outside the principal wall of the prison, and about fifty feet from the back wall of the building for lunatics ; but no odour proceeded from this pit when I crossed its cover on July 12th; it was about three-fourths full, chiefly of vegetable matters, and the odour was slight when the cover was removed.

Angust 6th, 1866.

Quacks in Chicago. The Chicago Post gives an account of a quack doctor who had practised as a physician in this city for twenty years, and had accumulated a handsome fortune. For a young girl who was dying with consumption, he ordered that a compound of coal-tar, vinegar, and assafoetida should be put in a large jar and kept constantly stirred by her side; and although the stench was horrible, the sufferer had to breathe it till she died. A patient was suffering from sore eyes. The learned physician told her, with great solemnity, that the fat which was to work the cure must be the fat of a cat. Furthermore, that the cat which gave the fat must be black. A single streak of white would spoil the charm, and the fat of a grey or brindled cat woul strike the patient stone blind. 